\title{
New DTC strategy of multi-machines single-inverter systems for electric vehicle traction applications
}

\author{
Taibi Ahmed ${ }^{1}$, Hartani Kada ${ }^{2}$, Allali Ahmed ${ }^{3}$ \\ ${ }^{1,3}$ Department of Electrical Engineering, University of Sciences and Technology, Algeria \\ ${ }^{2}$ Electrical Engineering Laboratory, University of Tahar Moulay of Saida, Algeria
}

\begin{tabular}{l} 
Article Info \\
\hline Article history: \\
Received Jan 17, 2019 \\
Revised Jul 22, 2019 \\
Accepted Aug 3, 2019 \\
\hline
\end{tabular}

Keywords:

Electric vehicle

In-wheel motor

In-wheel technology

Multi-machine control

Traction application

\begin{abstract}
In high power traction system applications two or more machines are fed by one converter. This topology results in a light, more compact and less costly system. These systems are called multi-machines single-converter systems. The problems posed by different electrical and mechanical couplings in these systems (MMS) affect various stages of the systems and require control strategy to reduce adverse effects. Control of multi-machines singleconverter systems is the subject of this paper. The studied MMS is an electric vehicle with four in-wheel PMS motors. A three-leg inverter supplies two permanent magnet synchronous machines which are connected to the front right and rear right wheels, and another inverter supplies the left side. Several methods have been proposed for the control of multi-machines singleinverter systems, the master-slave control structure seems best adapted for our traction system. In this paper, a new control structure based on DTC method is used for the control of bi-machine traction system of an EV. This new control has been implanted in simulation to analyze its robustness in the presence of the various load cases involved in our electric vehicle traction chain. Simulation results indicated that this structure control allowed the stability of the traction system.
\end{abstract}

This is an open access article under the CC BY-SA license.

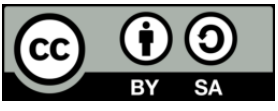

\section{Corresponding Author:}

Taibi Ahmed

Department of Electrical Engineering,

University of Sciences and Technology Mohamed Boudiaf,

USTO 31000 Oran, Algeria.

Email: taibiahmed36@yahoo.fr

\section{INTRODUCTION}

The in-wheel technology for electric vehicles is on the verge of exponential growth. The technology involves embedding a separate electric motor inside each wheel for the vehicle propulsion. By applying the traction force directly to each wheel and simplifying the drivetrain, the energy efficiency of electric vehicles (EVs) is enhanced [1]. More importantly, the in-wheel technology provides the opportunity for superior motion control of the vehicle due to the fact that electric motors can be controlled more precisely and significantly faster compared with internal combustion vehicles [1-3].

In an in-wheel vehicle, a separate electric machine is used at each driving wheel. The availability of a separate electric machine in each corner of in-wheel EVs opens the door for the development of innovative solutions for precise motion control of EVs. Separate electric machines used for the propulsion of the inwheel EV also provide regenerate power during normal braking to extend the vehicle range.

Multi-machine multi-converter systems can be considered as extensions of classical drives. In many applications, one motor is controlled by one converter. These systems are called single-machine single- 
converter systems. However, several methods have been proposed for the control of multi-machine singleconverter systems. In this case, a master slave based on DTC strategy has been developed.

Recently, permanent magnet synchronous motors (PMSM) have been extensively analyzed as feasible candidates for variable speed electric vehicle (EV) traction application [4]. In order to improve dynamic performance of the permanent magnet synchronous in-wheel motor, direct torque control (DTC) has been employed in this system. Because the DTC has many potential advantages [5, 6]. The DTC, which was presented by I Takahashi in 1986 for an induction machine [7], is based on the direct control of the torque and flux and involves non linear hysteresis controllers. Direct control strategies do not require the previously mentioned reference transformation to achieve a decoupled control of flux and torque. The currents of the machine are indirectly controlled through torque and flux control.

A new DTC algorithm is used for the control of a multi-machine system. Similar to a conventional DTC, the proposed method has two separate control loops. In the torque control loop, before selection of optimum voltage from the DTC look-up table, the system overall requirement is determined based on requirements of motors torque. Also, switchable master-slave control is used in the flux control loop. The method which is simulated for a two-parallel PMS machine system can be extended to a multi-machine system.

Sensorless control of permanent magnet synchronous motor drives is now receiving wide attention [8-11]. The model reference adaptive system (MRAS) represents one of the most attractive and popular solutions for sensorless control of AC drive. This project introduced the speed sensorless control of parallel connected dual PMSM by using MRAS technique [11].

In this paper, a new master slave direct torque control of permanent magnet synchronous motors based on speed MRAS observer is proposed for a multi-machine system in electric vehicle. A classical system with multi-inverter and multi-machine comprises a three-phase inverter for each machine to be controlled. Another approach consists in using only one three-phase inverter to supply several permanent magnet synchronous machines. A master slave based on DTC strategy has been developed. Simulation results in Matlab/Simulink indicated that the new DTC algorithm is well adapted for the synchronism of this system over a wide range of operations.

\section{MULTI-MACHINE DTC METHOD}

In the conventional DTC method, the flux and electromagnetic torque are controlled by adjusting the magnitude and position of the stator flux respectively $[6,7,12]$. This principle is used in the proposed method. In this proposed control strategy, there are two control loops; one for the stator flux control and one for the electromagnetic torque as can be seen either in the right or the left side of the Figure 1. The procedure of each control loop will be explained thoroughly in the following section of the paper.

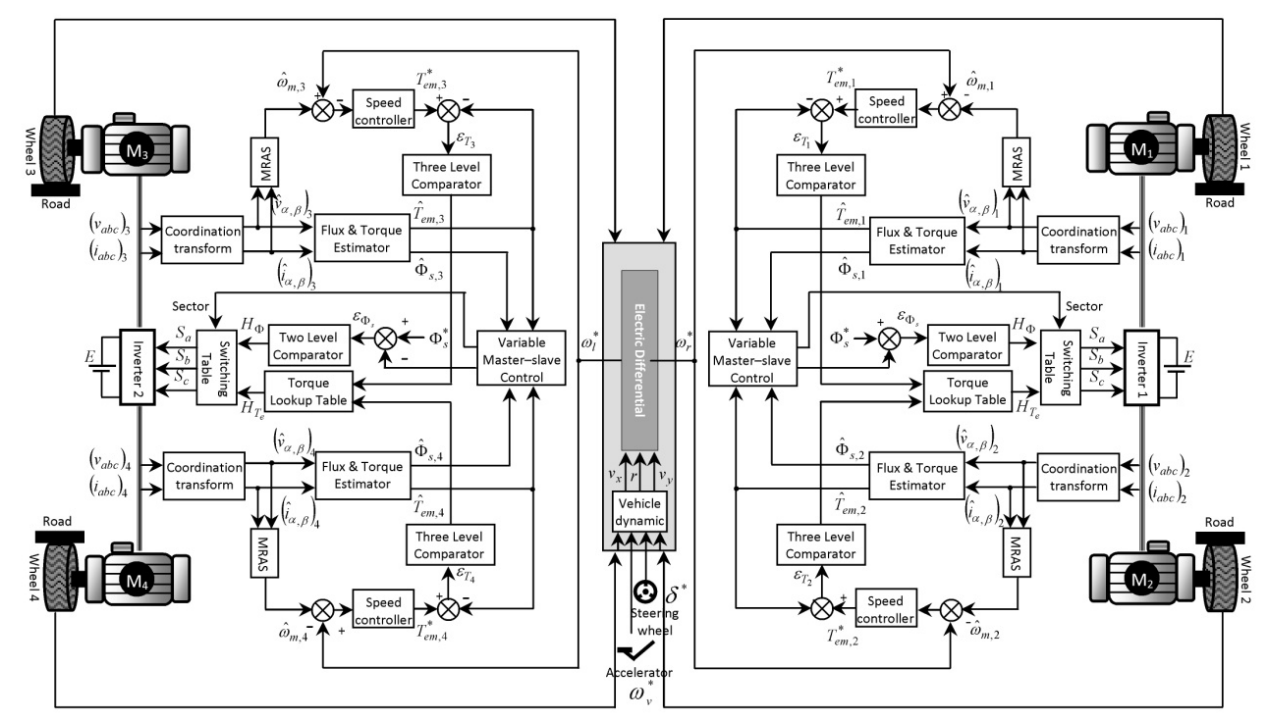

Figure 1. Block Diagram of the new multi-machine DTC in the traction drive of electric vehicle. 


\subsection{Electromagnetique torque control loop}

The new idea in the suggested control loop is to consider the motors torque requirements and system overall needs before selecting a voltage vector. This is done by designing a new look-up table in which a three-level comparator is used in the torque control loop. The procedure is explained below and shown in Table 1 where, $-1,0,1$ are the outputs of torque error comparator. Finally, using the output of this table and the output of the stator flux control loop, the appropriate voltage vector is selected based on the conventional DTC switching look-up table.

Table 1. Proposed table in torque control loop

\begin{tabular}{lllll} 
& \multicolumn{4}{c}{ Motor 2 } \\
& $H_{T e}$ & -1 & 0 & 1 \\
\hline Motor1 & -1 & -1 & -1 & 0 \\
& 0 & -1 & 0 & 1 \\
& 1 & 0 & 1 & 1 \\
\hline
\end{tabular}

\subsection{Stator flux control loop}

Before introducing the proposed idea, some issue must be explained regarding parallel PMS motors. As a result of applying one voltage vector, stator flux vector of all the parallel PMS motors will vary instantaneously in the same direction. Therefore:

$$
\frac{d \bar{\Phi}_{s}}{d t}=\bar{V}_{s}-R_{s} \bar{I}_{s}
$$

In the stator flux control loop, one should know that the flux of any machine can go beyond its rated value. According to (1) the stator flux of each permanent magnet synchronous motor surely depends on the applied voltage. In cases where parameters of the motors are different, or motors load are not the same, stator fluxes will be different, or motors load are not the same, stator fluxes will be different.

From (1) it can be seen that the stator flux vector only depends on stator resistance among all other parameters. Therefore, when stator resistance are the same, one expects to see the same flux for both machines. This is valid only at steady state, and during transients, the difference between the fluxes may be observed. This difference will also increase as motor speed decreases. For this reason, in cases where motor loads or stator resistances are different, speed reference cannot go below a certain value for speed control application. Thus, as the stator flux of one of the motors decreases, its torque generation capability will also decrease.

For these conditions, the mean control strategy cannot be used since the flux of the one machine can be saturated while its average value is equal to the reference value. Therefore, the master-slave control technique can be used for the stator flux control loop. In this way, only the stator flux of one motor is controlled. But the motor with the bigger stator flux magnitude has to be selected as the master, and its stator flux is set to the reference value. To prevent flux saturation at different situations, the master motor may change. Therefore, in the proposed method, switchable master-slave technique is employed for stator flux control.

In the conventional DTC, the final step is the selection of voltage vector using a look-up table. The voltage is selected with respect to the section of the stator flux. The proposed method uses the stator flux of the master motor for flux sector selection.

\section{SIMULATION ANALYSIS OF NEW CONTROL STRATEGY}

In order to ensure the stability of the system composed of two PMSM connected in parallel on the same inverter which uses the sensorless DTC "master-slave" structure, different loads are applied to both machines as shown on Figure 2(c). We can readily notice that whatever values of the torque provided by the two machines, the system is always stable.

The master machine is the one that provides the highest torque and the difference in position between the two machines corresponds to the theoretical basis $\theta_{1}<\theta_{2}$ when the highest torque is provided by PMSM1.For the speeds of the two machines ( Figure 2 (a)), whether master or slave, there is a close follow up of the reference speed imposed by the control strategy whatever is the value of the load applied. We notice that the difference between the two speeds has very satisfactory rates, which indicates the good perfection in swapping the master and slave motors according to the control behavior when disturbances 
occur. We notice fast response of electromagnetic torques of the two motors (master and slave) when we apply different loads as shown in Figure 2 (b), this confirms the fast and good management in master and slave under the conditions laid down in the algorithm of the control. We remark the fast response of electromagnetic torque of the two motors (master and slave) when applying different loads, Figure 2 (b), which confirms the speed and good alternation in master and slave under the conditions laid down in the algorithm control.

The phase currents of the two machines present good waveforms and confirm the responses of the motors as far as the changes in loads are concerned. Figure 2 (e) and (f) which represent the waveforms of the stator magnetic flux show good magnetic stability of both machines which ensures a good behavior that was imposed by the DTC control "master-slave" to the two machines against all disturbances. The simulation results of this proposed method offers better steady state response.

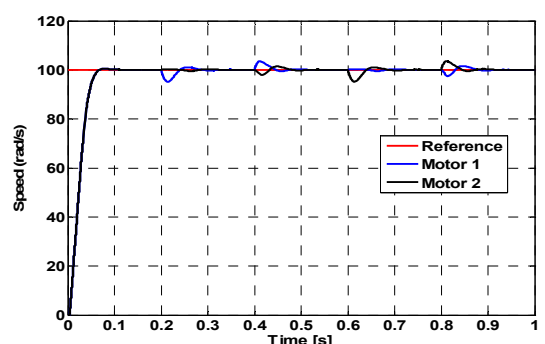

(a)

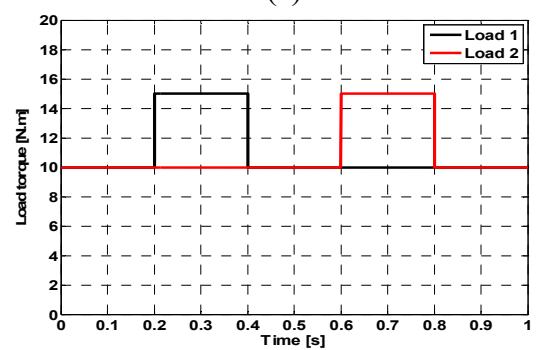

(c)

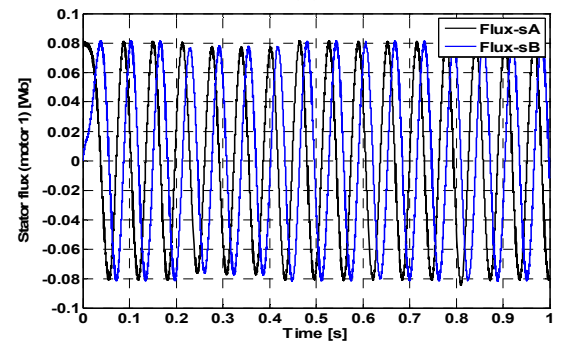

(e)

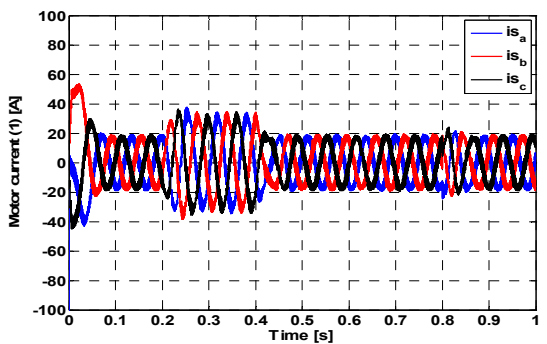

(g)

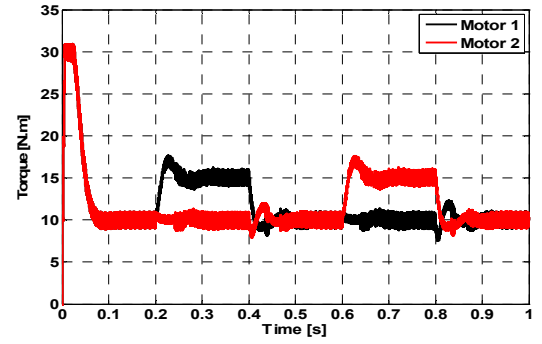

(b)

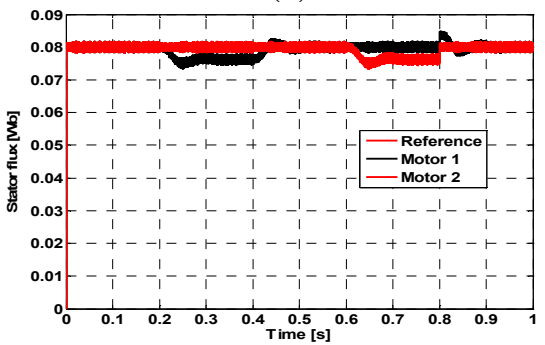

(d)

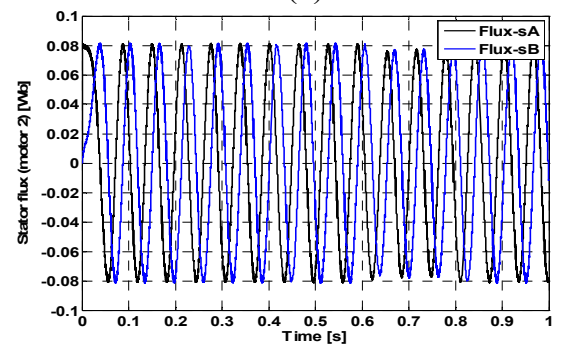

(f)

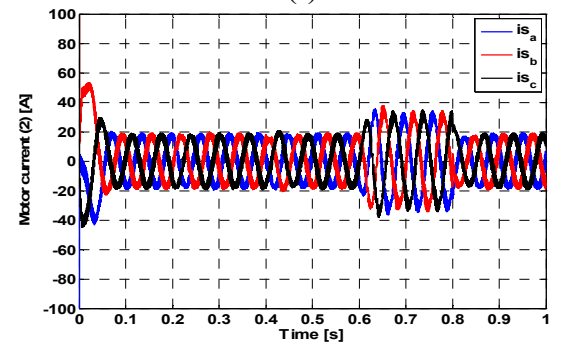

(h)

Figure 2. Speed, torque, stator flux and motor current of two motors with proposed method using load change 


\section{VEHICLE DYNAMICS}

The vehicle dynamics are described by the longitudinal velocity, lateral velocity and yaw rate as follows [13-17] :

$$
\begin{aligned}
\&= & v_{y} r+\frac{F_{t 1}+F_{t 2}+F_{t 3}+F_{t 4}-F_{r e s}}{M_{v}} \\
& +\frac{C_{f} \delta}{M_{v}}\left(\frac{v_{y}+r l_{r}}{v_{x}}-\delta\right) \\
\&= & \left(-\frac{C_{r}+C_{f}}{M_{v} v_{x}}\right) v_{y}+\left(\frac{C_{r} l_{r}+C_{f} l_{f}}{M_{v} v_{x}}-v_{x}\right) r+\frac{C_{f}}{M_{v}} \delta \\
\&= & \left(\frac{C_{r} l_{r}-C_{f} l_{f}}{J_{v} v_{x}}\right) v_{y}-\left(\frac{C_{r} l_{r}^{2}+C_{f} l_{f}^{2}}{J_{v} v_{x}}\right) r+\frac{C_{f} l_{f}}{J_{v}} \delta \\
& +\frac{d}{J_{v}}\left(F_{t 1}+F_{t 2}-F_{t 3}-F_{t 4}\right)
\end{aligned}
$$

Equation (3) indicates the vehicle resistance opposing its movement includes rolling resistance of the tires $F_{r r}$, aerodynamic drag resistance $F_{\text {aero }}$, and grading resistance $F_{c}$. All of the resistance will be discussed in detail in [18-22].

$$
F_{r e s}=F_{r r}+F_{\text {aero }}+F_{c}
$$

where

$$
\begin{aligned}
& F_{\text {aero }}=\frac{1}{2} \rho S_{f} C_{p x} V_{c g}^{2} \\
& F_{c}=M_{v} g \sin \left(\alpha_{p}\right) \\
& F_{r r}=C_{r r} M_{v} g
\end{aligned}
$$

The longitudinal forces for the four in-wheel motors can be calculated using the following equation:

$$
F_{t i}=\frac{g M_{v}}{4} \mu_{i} \cos \left(\alpha_{p}\right), i \in[1, \ldots, 4]
$$

The drive system model can be described by the following mechanical equations:

$$
\begin{array}{ll}
T_{r i}=F_{t i} R_{\omega}-N_{f} d_{z} & , i \in[1,3] \\
T_{r i}=F_{t i} R_{\omega}-N_{r} d_{z} & , i \in[2,4]
\end{array}
$$

Where $T_{r i}$ is the resistive torque; $N_{f}, N_{r}$ are the front and rear normal forces and have the following expressions:

$$
\begin{aligned}
& N_{f}=\frac{M_{v} g}{2}\left(\frac{l_{r}}{L}-\frac{h_{c g}}{L_{g}} \frac{d V_{c g}}{d t} \alpha_{p}-\frac{h_{c g}}{L} \alpha_{p}\right) \\
& N_{r}=\frac{M_{v} g}{2}\left(\frac{l_{f}}{L}+\frac{h_{c g}}{L_{g}} \frac{d V_{c g}}{d t} \alpha_{p}+\frac{h_{c g}}{L} \alpha_{p}\right),
\end{aligned}
$$

With a linear tire model, the front and rear cornering forces can be expressed as the product of the cornering stiffness $\left(C_{f}, C_{r}\right)$ and the sideslip angle $\left(\alpha_{f}, \alpha_{r}\right)$.

$$
\begin{aligned}
& F_{y f}=-C_{f} \alpha_{f} \\
& F_{y r}=-C_{r} \alpha_{r}
\end{aligned}
$$


The sideslip angles of the wheels can be easily expressed in terms of the longitudinal, lateral, and angular velocities, as well as the steering angle $\delta$. Explicit expressions of the sideslip angles for the front and rear axles are represented by . (10).

$$
\begin{aligned}
& \alpha_{f}=\tan ^{-1}\left(\frac{v_{y}+l_{f} r}{v_{x}}\right)-\delta \\
& \alpha_{r}=\tan ^{-1}\left(\frac{v_{y}-l_{r} r}{v_{x}}\right)
\end{aligned}
$$

The longitudinal slip can be defined for the four wheels as:

$$
\lambda_{i}=\frac{R_{\omega} \omega_{i}-u_{t i}}{\max \left(R_{\omega} \omega_{i}, u_{t i}\right)}, i \in[1, \ldots, 4]
$$

where:

$i=1,2,3$, and 4 correspond to the front left, front right, rear left, and rear right $(=l f, f r, r l, r r)$ wheels, respectively; $R_{\omega}$ is the wheel radius; $\omega_{i}$ is the angular velocity of the in-wheel motor; and $v$ is the linear speed at which the contact zone moves on the ground.

The interrelationships between the slip ratio $\lambda$ and the traction coefficient $\mu$ can be described by various formulas. In this study, the widely adopted magic formula $[15,23]$ is applied to describe the relationship between the slip and traction forces and to build a vehicle model for the following simulations, as shown in (11) [24, 25].

$$
\mu=c_{1}\left(\sin \left(c_{2} \tan ^{-1}\left(c_{3} \lambda-c_{4}\left(c_{3} \lambda-\tan ^{-1}\left(c_{3} \lambda\right)\right)\right)\right)\right)
$$

The coefficient sets of $c_{1}, c_{2}, c_{3}$ and $c_{4}$ are defined in (21).

\section{SIMULATION RESULTS}

The structure of the EV in this study is composed of four in-wheel motors (i.e., PMSMs) mounted in each wheel, as shown in Figure 3. Therefore, the wheel torque for each wheel can be controlled completely and independently for vehicle motion control. Each two in-wheel PMSMs are connected in parallel on the same inverter supplied by DC voltage source which are controlled by the sensorless master-slave DTC structure, Figure 1.

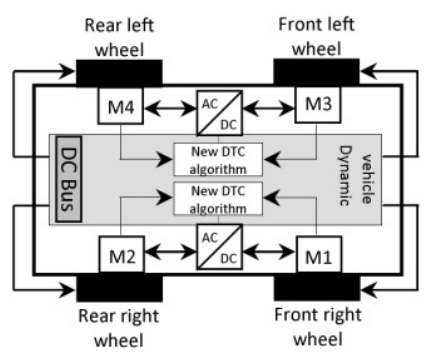

Figure 3. Configuration of an EV studied.

Table 3 summarizes the vehicle characteristics and parameters numerical values. The parameters of the PMSMs are given in Table 2. The proposed traction system uses the vehicle speed, the slope angle and the steering angle as input parameters and calculates the required inner and outer speeds.

Int J Pow Elec \& Dri Syst, Vol. 11, No. 2, June 2020 : $641-650$ 
Table 2. Motor parameters

\begin{tabular}{clc}
\hline Symbol & \multicolumn{1}{c}{ Quantity } & Value \\
\hline$R_{s}$ & resistance & $0,03 \Omega$ \\
$L_{d}$ & d-axis inductance & $0,2 \mathrm{mH}$ \\
$L_{q}$ & q-axis inductance & $0,2 \mathrm{mH}$ \\
$\Phi_{f}$ & permanent magnet & $0,08 \mathrm{~Wb}$ \\
$p$ & flux & 4 \\
\hline
\end{tabular}

Table 3. Electric vehicle parameters

\begin{tabular}{|c|c|c|}
\hline Symbol & Quantity & Value \\
\hline$M_{v}$ & vehicle mass & $1562 \mathrm{~kg}$ \\
\hline$J_{v}$ & vehicle inertia & 2630 kg.m ${ }^{2}$ \\
\hline$J_{\omega}$ & wheel inertia & 1,284 kg.m $\mathrm{m}^{2}$ \\
\hline$L_{f}$ & distance from the CG to front axle & $1,104 \mathrm{~m}$ \\
\hline$L_{r}$ & distance from the CG to rear axle & $1,421 \mathrm{~m}$ \\
\hline$h_{c g}$ & heigh of the vehicle ctroid (CG) & $0,5 \mathrm{~m}$ \\
\hline$S_{f}$ & frontal area of vehicle & $2,04 \mathrm{~m}^{2}$ \\
\hline$\rho$ & air density & $1,2 \mathrm{~kg} \cdot \mathrm{m}^{-3}$ \\
\hline$C_{p x}$ & drag coefficient & 0,25 \\
\hline$C_{r r}$ & rolling resistance coefficient & 0,01 \\
\hline$C_{f}$ & $\begin{array}{l}\text { longitudinal stiffness of each tire } \\
\text { lateral }\end{array}$ & $37407 \mathrm{~N} / \mathrm{rad}$ \\
\hline$C_{r}$ & lateral stiffness of each tire lateral & $51918 \mathrm{~N} / \mathrm{rad}$ \\
\hline$R_{\omega}$ & wheel radius & $0,294 \mathrm{~m}$ \\
\hline
\end{tabular}

The common reference speed $\omega^{*}$ is then set by the accelerator pedal command. The actual reference speeds for the left drives $\left(\omega_{3}^{*}, \omega_{4}^{*}\right)$ and the right drives $\left(\omega_{1}^{*}, \omega_{2}^{*}\right)$ can then be obtained by adjusting the common reference speed $\omega^{*}$ using the steering angle signal. When the steering angle is equal to zero, the electric vehicle drives on the straight road and the electronic differential does not need to work. On the other hand, if the steering angle changes, it indicates that the vehicle is making a turn and the electronic differential provides the difference of speed for the four in-wheel motors while the vehicle is performing a turn, which will result on the best stability of vehicle in the curved trajectory of the road.

The vehicle speed starts from zero to the chosen reference speed. The steering angle input is shown in Figure 4 corresponds to a right turn for four seconds, which will be the reference steering input for simulations. The vehicle turns to the right at $\mathrm{t}=5 \mathrm{~s}$, and when the steering angle reaches its maximum value at $\mathrm{t}=8 \mathrm{~s}$, and still be maintained at the mentioned value about 4 seconds and then it is brought to zero at $\mathrm{t}=15 \mathrm{~s}$.

Figure 5 shows the rotational speeds of the in-wheel motors. We notice that they have the same speed variations from the start up to the establishment of the steady state speeds as long as the vehicle runs on a straight path. During the steering, the motors (M1 and M2) located outside of the turn's curvature, rotate at higher speeds than motors (M3 and M4).

A good tracking of the longitudinal velocity of the vehicle can be observed in Figure 6 . The response of the speeds of the 4 driving wheels of the vehicle is shown in Figure 9. From Figures. 7 and 8 , the lateral velocity $v_{y}$ and the yaw moment $r$ depend on the steering command of the driver. These two speeds occur only during cornering and they vanish when the vehicle is travelling on a straight road.

The Figure 11 shows the difference in the traction forces generated by the motors of the front axle (M1 and M3) and the two motors of the rear axle (M2 and M4) during the completion of turn. First, we notice high traction forces are provided by the motors for moving the vehicle from start up. This seems logical since these forces must overcome the overall resisting forces to the movement of the vehicle. Therefore, the stability is maintained during the vehicle turn.

Figure 12 illustrates the variation of the electromagnetic torque of the motors. We have first, a high torque during the start up, the motors maintain these high electromagnetic torques from start up until the time their stabilized speeds are reached. At this time, the motor torques begin to decrease and then they stabilize at a certain set point. During the steering, the electromagnetic torques developed by the motors (M3 and M4) 
are higher than those of the motors (M1 and M2) as can be clearly seen in Figure 12. It can be observed that the torques of the outer motors are greater than that of the inner ones.

Simulation results indicate that the performance of the proposed method in control of four in-wheel motors traction system is favourable and offers good response at steady state.

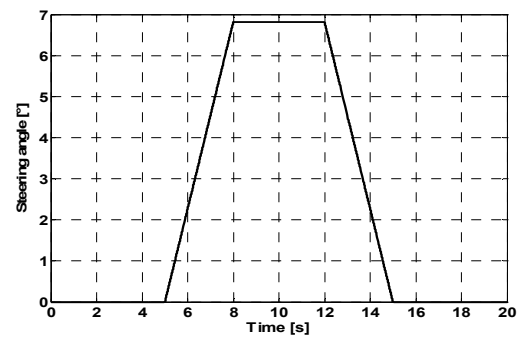

Figure 4. Steering angle input

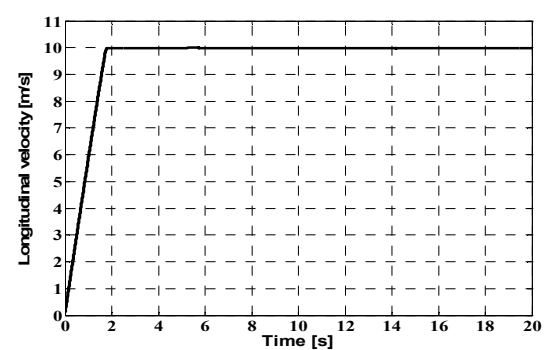

Figure 6. Longitudinal velocity

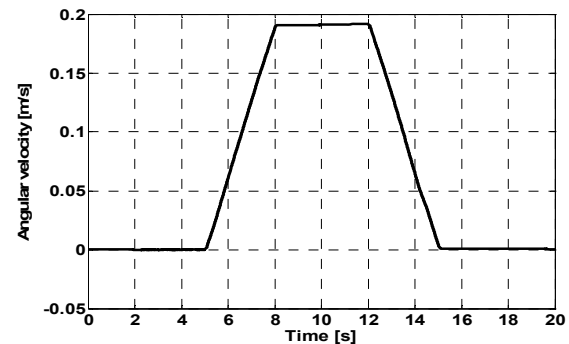

Figure 8. Angular velocity

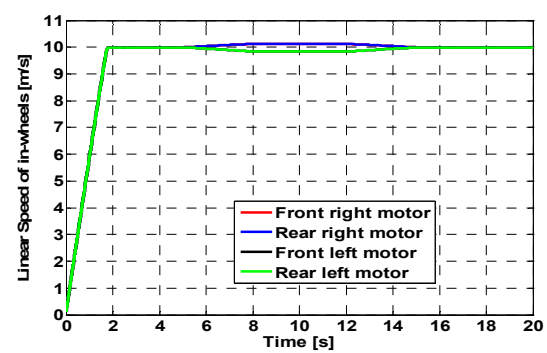

Figure 10. Linear speed of in-wheels

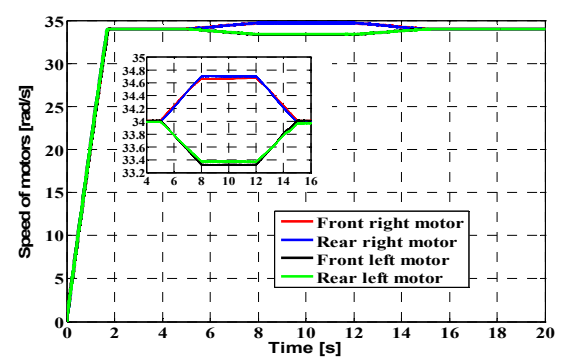

Figure 5. Rotational speed of motors

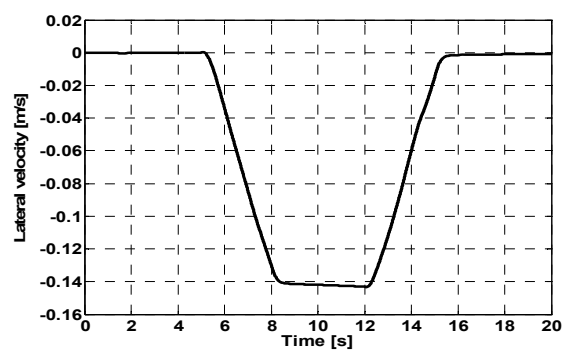

Figure 7. Lateral velocity

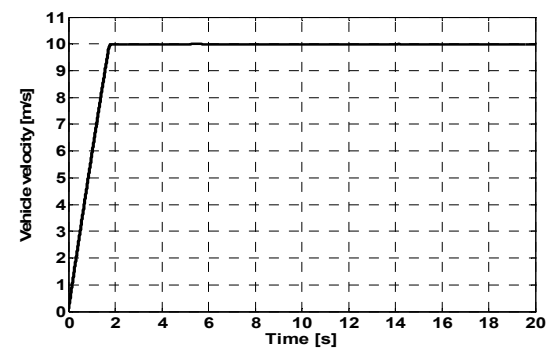

Figure 9. Linear velocity of vehicle

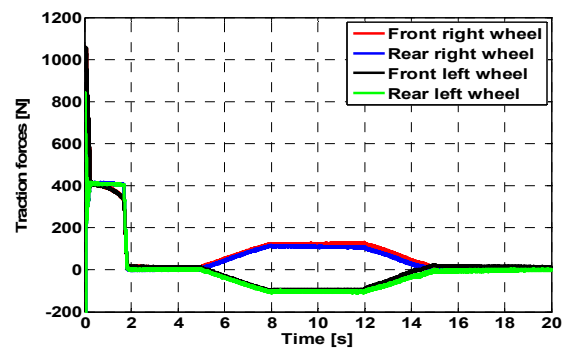

Figure 11. Traction forces 


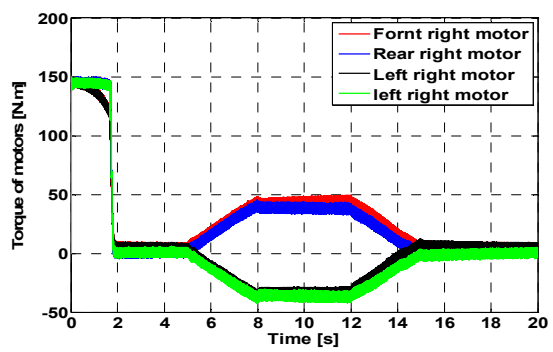

Figure 12. Torque of motors

\section{CONCLUSIONS}

Several methods have been proposed to control of multi-machine single-inverter systems. In this paper, a new technique improving the control performances for bi-machine single-inverter system in the traction drive of electric vehicles is proposed. The entire system is simulated by Matlab/Simulink. The simulation results show the effectiveness of the new multi-machine robust control based on an electric differential used in EV applications.

\section{REFERENCES}

[1] K. Cakir and A. Sabanovic, "In-wheel motor design for electric vehicles," in Advanced Motion Control, 2006. 9th IEEE International Workshop on, pp. 613-618, 2006.

[2] Y. Hori, "Future vehicle driven by electricity and control-research on four-wheel-motored" UOT Electric March II"," IEEE Transactions on Industrial Electronics, vol. 51, pp. 954-962, 2004.

[3] S.-i. Sakai, H. Sado, and Y. Hori, "Motion control in an electric vehicle with four independently driven in-wheel motors," IEEE/ASME Transactions on mechatronics, vol. 4, pp. 9-16, 1999.

[4] M. A. Rahman and R. Qin, "A permanent magnet hysteresis hybrid synchronous motor for electric vehicles," IEEE Transactions on Industrial Electronics, vol. 44, pp. 46-53, 1997.

[5] L. Tang, L. Zhong, M. F. Rahman, and Y. Hu, "A novel direct torque control for interior permanent-magnet synchronous machine drive with low ripple in torque and flux-a speed-sensorless approach," IEEE Transactions on industry applications, vol. 39, pp. 1748-1756, 2003.

[6] K. Hartani, Y. Miloud, and A. Miloudi, "Improved direct torque control of permanent magnet synchronous electrical vehicle motor with proportional-integral resistance estimator," Journal of Electrical Engineering and Technology, vol. 5, pp. 451-461, 2010.

[7] I. Takahashi and T. Noguchi, "A new quick-response and high-efficiency control strategy of an induction motor," IEEE Transactions on Industry applications, pp. 820-827, 1986.

[8] R. Yan, B. Li, and F. Zhou, "Sensorless control of PMSMs based on parameter-optimized MRAS speed observer," in Automation and Logistics, 2008. ICAL 2008. IEEE International Conference on, pp. 1573-1578, 2008.

[9] X. Xiang and Y. He, "Sensorless operation of PMSM based on hybrid rotor position self-sensing scheme," in Electrical Machines and Systems, 2007. ICEMS. International Conference on, pp. 714-718, 2007.

[10] X. Xiang and Y. He, "Sensorless operation of PMSM based on hybrid rotor position self-sensing scheme," in 2007 International Conference on Electrical Machines and Systems (ICEMS), pp. 714-718, 2007.

[11] K. Hartani, F. Maata, and A. Merah, "Sensorless master-slave direct torque control of permanent magnet synchronous motors based on speed MRAS observer in electric vehicle," Res. J. Appl. Sci. Eng. Technol, vol. 7, pp. 5034-5048, 2014.

[12] A. Draou and K. Hartani, "A novel direct torque control scheme for PMSM for improving quality in torque and flux," system, vol. 10, p. 12, 2012.

[13] E. Esmailzadeh, G. Vossoughi, and A. Goodarzi, "Dynamic modeling and analysis of a four motorized wheels electric vehicle," Vehicle System Dynamics, vol. 35, pp. 163-194, 2001.

[14] G. Genta, Motor vehicle dynamics: modeling and simulation, World Scientific, vol. 431997.

[15] M. h. Sekour, K. Hartani, A. Draou, and A. Allali, "Sensorless fuzzy direct torque control for high performance electric vehicle with four in-wheel motors," Journal of Electrical Engineering and Technology, vol. 8, pp. 530-543, 2013.

[16] A. Merah and K. Hartani, "Shared steering control between a human and an automation designed for low curvature road," International journal of vehicle safety, vol. 9, pp. 136-158, 2016.

[17] M. Khalfaoui, K. Hartani, A. Merah, and N. Aouadj, "Development of shared steering torque system of electric vehicles in presence of driver behaviour estimation," International Journal of Vehicle Autonomous Systems, vol. 14, pp. 18-39, 2018.

[18] T. Gillespie, "Fundamentals of Vehicle Dynamics, ; Society of Automotive Engineers Inc.: Warrendale, PA, USA, 1992," ISBN 978-1-56091-199-9. 
[19] M. Eshani, Y. Gao, S. E. Gay, and A. Emadi, "Modern electric, hybrid electric and fuel cell vehicles," Fundamentals, Theory, and Design. Boca Raton, FL: CRC, 2005.

[20] H. Pacejka, Tire and vehicle dynamics: Elsevier, 2005.

[21] R. Rajamani, Vehicle dynamics and control: Springer Science \& Business Media, 2011.

[22] J. Y. Wong, Theory of ground vehicles: John Wiley \& Sons, 2008.

[23] H. B. Pacejka and E. Bakker, "The magic formula tyre model," Vehicle system dynamics, vol. 21, pp. 1-18, 1992.

[24] K. Hartani, M. Khalfaoui, A. Merah, and N. Aouadj, "A Robust Wheel Slip Control Design with Radius Dynamics Observer for EV," SAE Int. J. Veh. Dyn., Stab., and NVH, vol. 2, 2018.

[25] K. Hartani, M. Bourahla, and Y. Miloud, "New antiskid control for electric vehicle using behaviour model control based on energetic macroscopic representation," Journal of Electrical Engineering, vol. 59, pp. 225-233, 2008.

\section{BIOGRAPHIES OF AUTHORS}

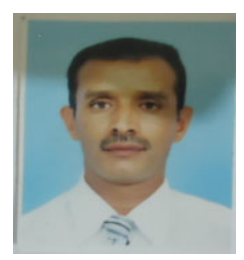

Ahmed TAIBI was born in Saida (Algeria) in 1967.

He graduated the University of Saida (Algeria), in 2000. He obtained a diploma of engineer in Electrotechnic in 1998. He received his master in Electrical Control at University of Sciences and Technology of Oran (Algeria) from 2010 at 2012. He is an assistant professor at university of Saida. His fields of interest include: multimachines multiconverters systems, , Traction control system, control for electric and hybrid vehicles.

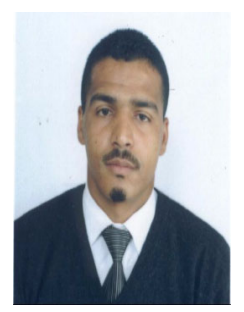

Kada Hartani was born in Saida, Algeria in 1976. He obtained his Doctorate in Electrical Control from the University of Sciences and Technology (USTO), Oran, Algeria, in 2007; M.S. in electrical control from the University of Sciences and Technology (USTO), Oran, Algeria, 2003; B.S. in Electrotechnical Engineering from the University of Saida, Algeria, in 1997. Currently, he is a Professor in electrical control and director of Electrotechnical Engineering Laboratory at the University of Saida, Algeria. His fields of interest include: multi-machines multi-converters systems, antilock brake system, traction control system and anti-skid control for electric vehicle. His fields of interest include multi-machine multi-converter systems, antilock brake system, traction control system, and anti-skid control for electric vehicle.

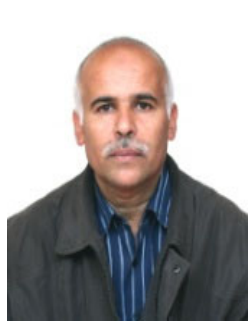

Ahmed ALLALI was born in Mecheria Naama (Algeria) in 1960.

In 1987 he graduated at the Electrotechnical Department of the Faculty of Electrical Engineering at University (USTO) in Algeria, in 1987. He defended his "Magister". In the field of optimal power flow problems in 1990; his thesis title was "Optimal Distribution of Active Powers Using Linear Programming with Losses Cost Minimization", and the PhD degree from in 2006; His scientific research is focusing a control and real time simulation of power systems, and study of the Dynamic stability of the networks electrical supply. Actually he is interested in power electronics in particular to the facts and in renewable energies (wind and solar energy). He is currently Professor of electrical engineering at The University of USTO (Algeria). 